\title{
Predictors of variceal bleeding: an analysis of clinical, endoscopic, and haemodynamic variables, with special reference to intravariceal pressure
}

\author{
$S$ K SARIN, K R SUNDARAM, AND R K AHUJA \\ From the Department of Gastroenterology, G B Pant Hospital and Department of Biostatistics, All India \\ Institute of Medical Sciences, New Delhi, India
}

\begin{abstract}
Summary To assist in the prediction of variceal bleeding we examined 12 clinical, endoscopic and haemodynamic variables in 126 patients with portal hypertension (72 bleeders and 54 non-bleeders). Multiple regression and discriminant analysis were utilised for 101 patients. Stepwise regression among the 12 variables explained only $54 \%$ of the variability existing between bleeders and nonbleeders. Six of the 12 variables accounted for $51 \%$ of the total bleeder/non-bleeder variability. A predicting equation was evolved $\{Y p=-0 \cdot 60+0 \cdot 19 \times 1$ (colour of varices) $+0 \cdot 16 \times 2$ (cherry red spots) + 0.03 X3 (red wale, markings) + 0.01 X4 (haematocystic spots) + 0.15 X5 (Conn's grading of variceal size) $+0.03 \times 6$ (intravariceal pressure) $\}$. Of the six variables used, variceal size indicated $35 \%$, and intravariceal pressure accounted for $12 \%$, of the explained variability between bleeders and non-bleeders. The presence of the three red colour signs and the colour of the varices accounted for only $3 \%$ and $1 \%$ respectively of the total explained variation. Using the discriminant function analysis, we were able to correctly identify $85 \%$ of the bleeders and $81 \%$ of the non-bleeders. Additional studies are required to detect the variables responsible for the unexplained variability $(46 \%)$ between bleeders and non-bleeders.
\end{abstract}

To be able to correctly identify the variceal bleeders before the acute episodes of bleeding would greatly assist in improving the morbidity and mortality of patients with portal hypertension. In the past, many attempts have been made to identify endoscopic features which would predict variceal bleeding. Large varices have been shown to bleed more often than small varices. ${ }^{1-3}$ Different conventions for grading variceal size are, however, in vogue and little is known about their relative value. ${ }^{+8}$ In addition to size, a number of endoscopic signs like cherry red spots, ${ }^{9}$ varices overlying varices, ${ }^{10}$ red plugs, ${ }^{11}$ red wale markings, blue varices, ${ }^{12}$ etc, have been proposed to describe patients with high risk of variceal bleeding. ${ }^{13}$ The validity of these endoscopic signs studied individually or collectively, remains to be assessed. Moreover, subjective bias and inter-

Address for correspondence: Dr S K Sarin. Associate Professor, Dept of Gastroenterology, G B Pant Hospital, New Delhi 110002, India.

Accepted for publication 5 April 1989. observer variation in the endoscopic evaluation of these predictors cannot be excluded.'

Portal pressure and hepatic venous pressure gradient do not correlate well and do not accurately predict variceal bleeding. ${ }^{214}$ The recently described portal venous-oesophageal luminal gradient is not helpful in differentiating variceal bleeders from nonbleeders. ${ }^{15}$ In search of a closer assessment of the actual intraluminal pressure, attempts have been made to study the intravariceal pressure by indirect ${ }^{\text {to }}$ and direct puncture ${ }^{17}$ techniques. Whether intravariceal pressure influences variceal bleeding and correlates with the other suggested endoscopic predictors is not clearly known.

The present investigation was initiated with the following aims - (i) to evaluate the usefulness of endoscopic signs of variceal bleeding, (ii) to study and compare the significance of intravariceal pressure measurements, and finally (iii) whether it is feasible to identify variceal bleeders from nonbleeders. 


\section{Methods}

PATIENTS

One hundred and twenty six consecutive patients with portal hypertension, seen between November 1986 and March 1988 were included in the study. These patients were referred either for upper gastrointestinal bleeding, chronic liver disease, moderate splenomegaly or significant anaemia and were found to have oesophageal varices at endoscopy. A detailed history was taken to evaluate the episodes of upper gastrointestinal bleeding in the past. Seventy two $(57.1 \%)$ patients had a history of one or more episodes of upper gastrointestinal bleeding and 54 $(42.9 \%)$ patients were non-bleeders. Twelve of the 72 patients $(17 \%)$ had a past history of variceal bleeding. The remaining patients had presented either with an active (nine patients) upper gastrointestinal bleeding or with a history of recent (within 72 hours) bleeding (51 patients). An upper gastrointestinal endoscopy was done within 12-24 hours in all the recent or active bleeders and except for one patient there was no evidence of a non-variceal mucosal source of upper gastrointestinal bleeding.

Portal hypertension was caused by cirrhosis of liver in 59, non-cirrhotic portal fibrosis in 35 , extrahepatic portal vein obstruction in 30 , hepatoma in one, and hepatic outflow obstruction in one (Table 1). There were $95(75 \%)$ men and $31(25 \%)$ women with a mean (SD) age of 28 (17) (range 1-70) years. While the diagnosis of cirrhosis was made on histological and clinical features, the diagnosis of non-cirrhotic portal fibrosis and extrahepatic portal vein obstruction was made according to the criteria described earlier. ${ }^{1 \times}$ Severity of liver disease was assessed using Child's criteria. ${ }^{14}$

Patients were informed about the nature of the study and consent was obtained. No patient was on regular sclerotherapy or on other treatment for portal hypertension.

\section{ENDOSCOPIC EVALUATION}

The endoscopic evaluation of oesophageal varices was done by two independent observers at the first endoscopy in non-bleeders, active, recent, and old bleeders. As sclerotherapy is our first line management for patients with active variceal bleeding, ${ }^{20}$ in five of the nine patients who had presented with an acute variceal bleed, emergency endoscopic sclerotherapy was carried out to control the bleeding and intravariceal pressure was measured three to seven days later at second endoscopy. In the other four patients, intravariceal pressure was measured before emergency sclerotherapy. Sengstaken-Blakemore tube was not used at any time for the control of variceal bleeding.
Table 1 Demographic profile of the patients

\begin{tabular}{|c|c|c|c|c|c|}
\hline \multirow[b]{2}{*}{ Parameter } & \multirow[b]{2}{*}{$\begin{array}{l}\text { Total } \\
\text { patients }\end{array}$} & \multicolumn{2}{|c|}{ Bleeders } & \multicolumn{2}{|c|}{ Non-Bleeders } \\
\hline & & $M: F$ & $\begin{array}{l}\text { Mean age (SD) } \\
\text { (yrs) }\end{array}$ & $M: F$ & $\begin{array}{l}\text { Mean age }(S D) \\
(\mathrm{yrs})\end{array}$ \\
\hline \multicolumn{6}{|c|}{ Aetiology of portal hypertension } \\
\hline Cirrhosis & 59 & $23: 3$ & $38 \cdot 2(13 \cdot 8)$ & $27: 6$ & $42 \cdot 5(12 \cdot 6)$ \\
\hline $\mathrm{NCPF}$ & 35 & $16: 7$ & $27 \cdot 2(5 \cdot 9)$ & $5: 7$ & $27 \cdot 1(11 \cdot 3)$ \\
\hline EHO & 30) & $16: 5$ & $9 \cdot 9(8 \cdot())$ & $7: 2$ & $8 \cdot 0(3 \cdot 8)$ \\
\hline HOFO & 1 & 1 & 53 & & \\
\hline Hepatoma & 1 & 1 & 55 & & \\
\hline \multicolumn{6}{|c|}{ Child's grade } \\
\hline A & 80 & \multicolumn{2}{|c|}{$48(67 \%)$} & \multicolumn{2}{|c|}{$32(59 \%)$} \\
\hline B & 30 & \multicolumn{2}{|c|}{$15(21 \%)$} & \multicolumn{2}{|c|}{$15(28 \%)$} \\
\hline C & 16 & \multicolumn{2}{|c|}{$9(12 \%)$} & \multicolumn{2}{|c|}{$7(13 \%)$} \\
\hline
\end{tabular}

M:F - male:female, NCPF - non-cirrhotic portal fibrosis, EHO extrahepatic portal vein obstruction, HOFO - hepatic outflow obstruction.

Variceal assessment was done using three independent grading systems - (i) Conn's grading - grade 1 to $4,{ }^{4}$ (ii) Westaby's grading - grade 1 to 3,5 and (iii) The Criteria of Japanese Research Society for Portal Hypertension. ${ }^{x}$ The endoscopic observations were recorded on a detailed form. While both Conn's and Westaby's grading, mainly assess the size of the oesophageal varices, the Japanese Research Society for Portal Hypertension criteria evaluate a number of other endoscopic signs which include - (a) fundamental colour of the varices: divided into white $(\mathrm{Cw})$ and blue $(\mathrm{Cb})$ colour, (b) red colour signs: dilated small vessels or microtelangiectasia on the variceal surface and was subdivided into cherry red spot, redwale marking and haematocystic spot. Depending on the number and extent of distribution, each of these three red colour signs was graded as absent $(-), 1+$, or $2+$, (c) form of varices: small straight varices $(\mathrm{F} 1)$, enlarged tortuous varices occupying less than one third of the oesophageal lumen (F2), and largest sized coil-shaped varices, occupying more than one third of the oesophageal lumen (F3), (d) location: the longitudinal extent of the varices and this was subdivided into varices which were located in the lower third of the oesophagus, locus inferior ( $\mathrm{Li})$, varices extending up to the tracheal bifurcation, locus medialis $(\mathrm{Lm})$, and varices which extended beyond the tracheal bifurcation, locus superior (Ls). In addition to these four main features, presence of oesophagitis (E) was also carefully looked for.

INTRAVARICEAI. PRESSURE MEASUREMENT Intravariceal pressure was recorded in 101 patients. In the non-bleeders, the procedure was carried out electively and care was taken to withdraw the endoscope only after ensuring adequate haemostasis at the puncture site. In an occasional patient, a small 
amount of alcohol was injected for sclerosis. In none of the patients overt upper gastrointestinal bleeding ensued due to intravariceal pressure measurement. In the bleeders, intravariceal pressure was measured before sclerotherapy. The intravariceal pressure was recorded by the direct variceal puncture technique as described earlier. ${ }^{17}$ In brief, after insertion through the endoscopic channel, an injector filled with absolute alcohol was used to puncture a variceal column within $5 \mathrm{~cm}$ of the cardia. Blood could be seen to flow up into the injector on puncturing the varix. As absolute alcohol is an aqueous solution and has the same specific gravity as water, it was used as a fluid medium for measuring variceal pressure as well as serving as a sclerosant. Intravariceal pressure was recorded when the patient was breathing normally without any retching, by connecting the injector to a fluid filled transducer and a Gould pressure

Table 2 Frequency and significance of different variables on variceal bleeding

\begin{tabular}{|c|c|c|c|c|c|}
\hline Variable & Bleeder & $\begin{array}{l}\text { Non- } \\
\text { bleeder }\end{array}$ & $\begin{array}{l}\text { Patients } \\
\text { (total) }\end{array}$ & $\begin{array}{l}\text { Patients } \\
\text { bleeding } \\
(\%)\end{array}$ & $p<$ \\
\hline \multicolumn{6}{|l|}{ Colour } \\
\hline Blue & 69 & 41 & 110 & 63 & $0 \cdot 001$ \\
\hline White & 3 & 13 & 16 & 19 & \\
\hline \multicolumn{6}{|l|}{ Cherry RS } \\
\hline Negative & 5 & 26 & 31 & 16 & 0.0001 \\
\hline Positive & 67 & 28 & 95 & 71 & \\
\hline \multicolumn{6}{|c|}{ R W Markings } \\
\hline Negative & 17 & 35 & 52 & 33 & 0.0001 \\
\hline Positive & 55 & 19 & 74 & 74 & \\
\hline \multicolumn{6}{|l|}{ H C Spots } \\
\hline Negative & 40 & 42 & 82 & 49 & $0.0(0) 1$ \\
\hline Positive & 32 & 12 & 44 & 73 & \\
\hline \multicolumn{6}{|l|}{ Form } \\
\hline $\mathrm{Fl}$ & 4 & 19 & 23 & 17 & $0 \cdot 00(01$ \\
\hline $\mathrm{F} 2$ & 42 & 30 & 72 & 58 & \\
\hline F3 & 26 & 5 & 31 & 84 & \\
\hline \multicolumn{6}{|l|}{ Length } \\
\hline $\mathrm{Li}$ & 2 & 10 & 12 & 17 & $0 \cdot 0001$ \\
\hline $\mathrm{Lm}$ & 40 & 36 & 76 & 53 & \\
\hline Ls & 30 & 8 & 38 & 79 & \\
\hline \multicolumn{6}{|l|}{ Conn's Gr } \\
\hline 1 & 1 & 5 & 6 & 17 & $0 \cdot(00) 1$ \\
\hline 2 & 10 & 29 & 39 & 26 & \\
\hline 3 & 33 & 16 & 49 & 67 & \\
\hline 4 & 28 & 4 & 32 & 88 & \\
\hline \multicolumn{6}{|c|}{ Westaby`s Gr } \\
\hline 1 & 3 & 17 & 20 & 15 & $0.0(0) 1$ \\
\hline 2 & 22 & 24 & 46 & 48 & \\
\hline 3 & 47 & 13 & 60 & 78 & \\
\hline \multicolumn{6}{|l|}{ Child's Gr } \\
\hline A & 48 & 32 & 80 & 60 & 0.65 \\
\hline B & 15 & 15 & 30 & 50 & \\
\hline $\mathrm{C}$ & 9 & 7 & 16 & 56 & \\
\hline
\end{tabular}

recorder. Two successive similar readings were taken. Intraoesophageal pressure was used as an internal zero reference point.

Assessment of endoscopic features and measurement of intravariceal pressure was done at the same session. The endoscopist was blinded to the history of variceal bleeding in the patients. In all, 12 parameters (clinical, endoscopic and haemodynamic) were evaluated to ascertain their predictability for variceal bleeding. These parameters included age, sex, variceal colour, presence of cherry red spots, red wale markings, haematocystic spots, variceal form, length, Conn's variceal grading, Westaby's variceal grading, Child's grade of liver disease, and intravariceal pressure. All these variables were compared between bleeders and non-bleeders. The rate of bleeding for each variable was independently calculated by finding out their percentage positivity in bleeders and non-bleeders.

STATISTICAL ANALYSIS

Univariate analysis was done by applying $\chi^{2}$ tests for all the independent variables except for intravariceal pressure, where Student's $t$ test was applied to compare bleeders with non-bleeders. Because of the small number of patients in certain variceal grades, for statistical evaluations of intravariceal pressure, Conn's variceal grade 1 and 2 patients were combined and compared with Conn's grade 3 and 4 and Westaby's grade 1 and 2 with grade 3 patients. Pearson's correlation between intravariceal pressure and variceal bleeding was also calculated. Multivariate analysis was done by applying step-wise multiple regression analysis with the help of the SAS programme using the forward option. This was followed by linear discriminant function analysis to classify bleeders and non-bleeders using the significant variables identified by the multiple regression.

\section{Results}

The demographic profile and the aetiology of portal hypertension in the variceal bleeders and nonbleeders is shown in Table 1. There was no significant difference in the mean age, sex distribution, and aetiology of portal hypertension between the two groups of patients. All 12 variables were individually and collectively analysed to assess their variability or the chance for correctly predicting variceal bleeding.

\section{SIZE OF VARICES}

According to Conn's and Westaby's grading systems, large varices were found to have bled significantly $(p<0.01)$ more often than small varices. Conn's grading was found to be somewhat superior to Westaby's as the largest varices (grade 4) recorded 
with the former had a higher bleeding rate $(88 \%)$ as compared with the largest varices (grade 3 ) recorded with the later system (78\%) (Table 2), the difference, however, was not significant. As Conn's and Westaby's grading systems only assess variceal size, for the discriminant function analysis only Conn's grading system was used. It explained the highest percentage variability $(35.1 \%)$ provided by any single variable.

\section{COLOUR OF VARICES}

While white coloured varices rarely bleed $(19 \%)$, blue varices had more often than not bled. The bleeding rate of blue coloured varices was $63 \%$, which was significantly $(\mathrm{p}<0.001)$ more than white varices. Using discriminant function analysis, however, variceal colour alone could explain only $0.9 \%$ variation.

\section{RED COLOUR SIGNS}

The three endoscopic signs studied, cherry red spots, red wale markings and haematocystic spots were significantly $(\mathrm{p}<0 \cdot 0001)$ more often present in bleeders than in non-bleeders (Table 2). When these features were present only in mild to moderate $(1+)$ degree, however, bleeders and non-bleeders could not be correctly separated. Therefore, for discriminant function analysis, only presence $(+)$ or absence $(-)$ of each of the three red colour signs was taken into account. The three endoscopic red colour signs together explained only $3.0 \%$ variability, the maximum contribution being from the presence of cherry red spots.

LOCATION OF VARICES

Rate of bleeding for varices extending up to locus

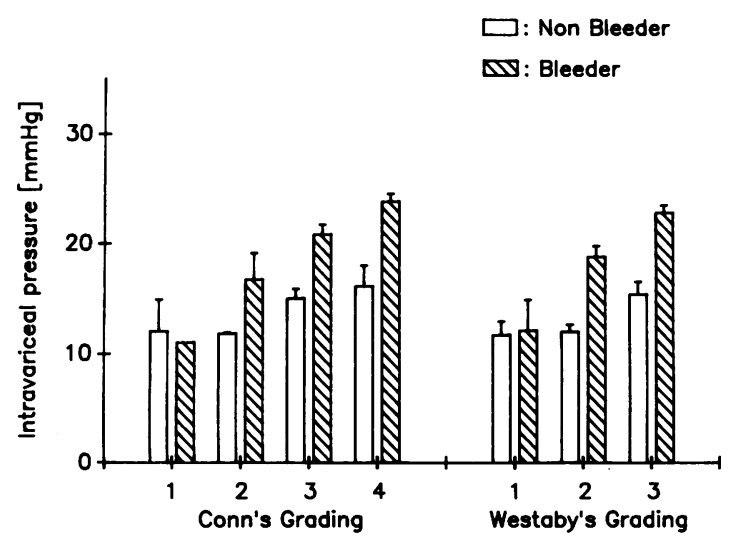

Fig. 1 Mean (SEM) intravariceal pressure in non-bleeders and bleeders with different variceal grades, according to Conn's and Westaby's classification. Statistical analysis is shown in Table 3 by combining the subgroups.
Table 3 Intravariceal pressure (mean (SEM)); grade of varices and variceal bleeding

\begin{tabular}{|c|c|c|c|c|c|}
\hline \multirow[b]{3}{*}{ Study group } & \multicolumn{5}{|c|}{ Intravariceal pressure $(\mathrm{mmHg})$} \\
\hline & \multicolumn{2}{|c|}{ Bleeders } & \multicolumn{2}{|c|}{ Non-Bleeders } & \multirow[b]{2}{*}{$p<$} \\
\hline & $n$ & $I V P$ & $n$ & $I V P$ & \\
\hline \multicolumn{6}{|l|}{ Conn’s gr } \\
\hline $\begin{array}{l}\text { Gr } 1+2 \\
\text { Gr } 3+4\end{array}$ & $\begin{array}{r}8 \\
52\end{array}$ & $\begin{array}{l}18.3(2.4) \\
21.8(0.8)\end{array}$ & $\begin{array}{l}28 \\
13\end{array}$ & $\begin{array}{l}12 \cdot 3(1 \cdot 1) \\
14 \cdot 2(1 \cdot 4)\end{array}$ & $\begin{array}{l}0.05 \\
0.001\end{array}$ \\
\hline $\mathrm{p}$ & & NS & & NS & \\
\hline \multicolumn{6}{|l|}{ Westaby’s gr } \\
\hline Gr 3 & 40 & $22 \cdot 6(0 \cdot 9)$ & 8 & $15 \cdot 1(1.9)$ & $0 \cdot(01$ \\
\hline $\mathrm{p}$ & & $<0.05$ & & NS & \\
\hline
\end{tabular}

superior was significantly $(\mathrm{p}<0.0001)$ more than the varices belonging to the other two groups (locus medialis and locus inferior). Only two $(17 \%)$ of the 12 patients with varices limited to the locus inferior had bled (Table 2). Length of varices was able to explain $0 \cdot 5 \%$ variation by applying discriminant function analysis.

FORM OF VARICES

An analysis of the rate of bleeding in relation to the form of varices showed that enlarged and tortuous (F3) varices bled significantly $(\mathrm{p}<0.0001)$ more often $(84 \%)$ than the straight $(\mathrm{F} 1)$ varices $(17 \%)$. For the form in between these two (F2), variceal bleeding was seen in $58 \%$ patients. Variceal form explained only $3 \%$ variability for predicting variceal bleeding.

\section{OESOPHAGITIS}

Endoscopic evidence of associated oesophagitis was seen only in one patient with oesophageal varices. It did not have any significance in predicting variceal haemorrhage.

\section{INTRA VARICEAL PRESSURE}

Intravariceal pressure recorded in 101 patients was significantly $(\mathrm{p}<0 \cdot 01)$ higher in bleeders $(21.4(5.9)$ $\mathrm{mmHg})$ than non-bleeders $(12.9(5.6) \mathrm{mmHg})$. A highly significant positive correlation $(r=0.59$, $\mathrm{p}<0.001$ ) was seen between variceal pressure and bleeding, indicating that patients with higher pressures bled more often. Variceal pressure in patients with different grades of varices is shown in Figure 1 and Table 3 . In non-bleeders, intravariceal pressure was comparable between different variceal grades. In the bleeding groups, however, patients with large varices (Conn's grade 3, 4 and Westaby's grade 3 ) had higher pressures than patients with small varices. The difference, however, reached significance only in Westaby's classification. On the other hand, bleeders under either classification had 
significantly higher intravariceal pressure as compared with non-bleeders with similar variceal grades (Table 3).

Intravariceal pressure was found to be significantly higher when patients with one or more red colour signs were compared with those in whom these signs were absent $(23.5(10.5) v 11.9(6.6) \mathrm{mmHg}$ respectively, $\mathrm{p}<0.001)$. Intravariceal pressure in variceal bleeder and non-bleeder patients because of different aetiologies of portal hypertension is shown in Figure 2. There was no significant difference in the mean (SD) intravariceal pressure in bleeders with portal hypertension caused by cirrhosis $(20.8(5 \cdot 5)$ $\mathrm{mmHg}$ ), non-cirrhotic portal fibrosis $(21.6(4.7)$ $\mathrm{mmHg}$ ), and extrahepatic portal vein obstruction $(23.0)(6 \cdot 6) \mathrm{mmHg})$. Similarly in non-bleeders, mean (SD) intravariceal pressure did not differ significantly in patients with cirrhosis $(11.4(5.6) \mathrm{mmHg})$, noncirrhotic portal fibrosis $(13.7(2.6) \mathrm{mmHg})$, and extrahepatic portal vein obstruction (12.8 (8.4) $\mathrm{mmHg}$ ). Using the discriminant function analysis, intravariceal pressure was found to be the second most important variable which could explain $11.8 \%$ variability.

STATUS OF THE LIVER DISEASE

The majority $(63 \%)$ of our patients had Child's A liver disease. There was no significant difference in the rate of bleeding between patients belonging to Child's A $(60 \%)$, B $(50 \%)$, and C $(56 \%)$ class of liver disease. On applying discriminant function analysis, Child's grading of liver disease was able to explain only $0.9 \%$ variability.

USE OF DISCRIMINANT FUNCTION ANALYSIS IN PREDICTING VARICEAL BLEEDING

In the next step, we used the potential of each variable in explaining the variation for predicting variceal bleeding. Discriminant function and stepwise multiple regression analyses were done in 101 patients, because the intravariceal pressure data in the remaining 25 ( 13 bleeders and 12 non-bleeders) were not available. For calculating the discriminant function equation, of the three variables for assessing the variceal size, only Conn's grading was used as it gave the maximum percentage variability. All the 12 variables taken together, could explain only $54 \%$ variability, the remaining $46 \%$ variation could not be explained by the parameters studied by us.

Six of the 12 variables provided $51 \%$ of the total variation and we therefore decided to use these six variables to develop a discriminant function equation for classifying variceal bleeders -

$$
\begin{gathered}
\mathrm{Yp}=-0 \cdot 60+0 \cdot 19 \times 1+0 \cdot 16 \times 2+0 \cdot 034 \times 3+0 \cdot 01 \times 4 \\
+0 \cdot 15 \times 5+0 \cdot 03 \times 6
\end{gathered}
$$

where $\mathrm{Yp}=$ value for predicting bleeder or non-

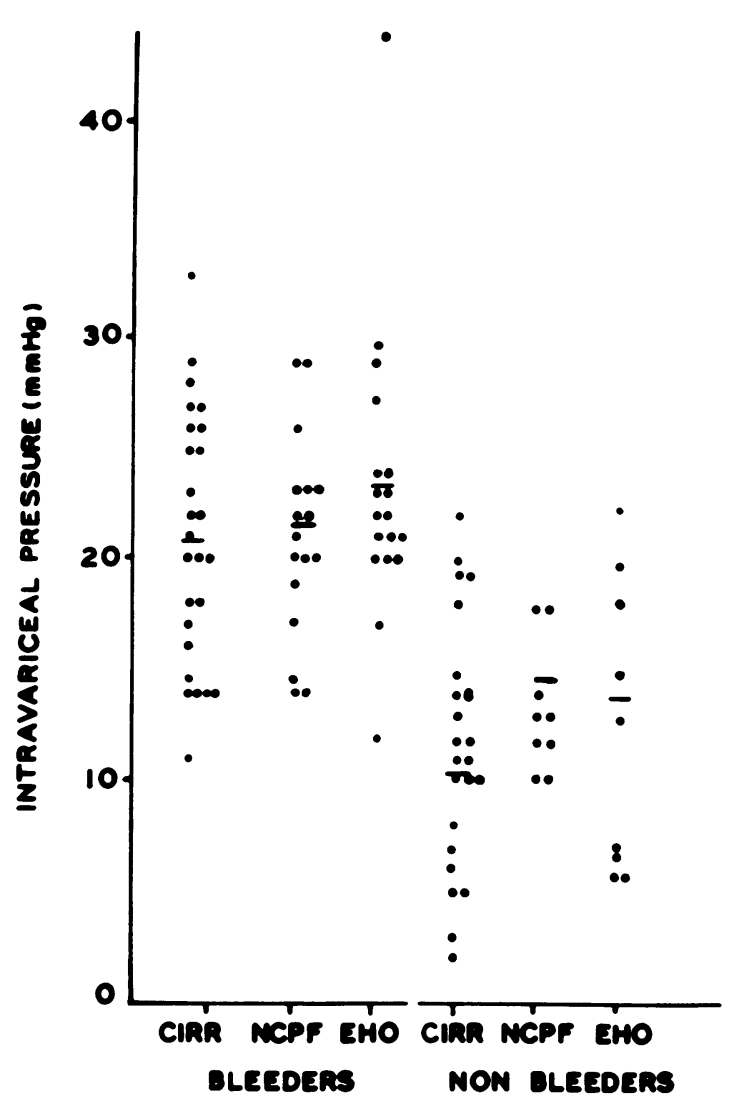

Fig. 2 Intravariceal pressure in variceal bleeders and nonbleeders with different aetiologies of portal hypertension (cirr = cirrhosis, NCPF=non-cirrhotic portal fibrosis, $E H O=$ extrahepatic portal vein obstruction).

bleeder, X1 - colour of varices, X2 - presence of cherry red spots on the varices, X3 - presence of red wale markings, $\mathrm{X} 4$ - presence of hematocystic spots, X5 - Conn's grading of the size of oesophageal varices and $\mathrm{X} 6$ - intravariceal pressure.

On substituting the values of these six variables for a patient, if the equation resulted in a value of more than $0 \cdot 5$, the patient was identified as a bleeder and if otherwise, then as a non-bleeder. Based on this discriminant function, $81 \%$ of the non-bleeders and $85 \%$ of the bleeders could be correctly classified.

\section{Discussion}

The search for the mechanisms of variceal rupture and the factors influencing variceal bleeding continues. ${ }^{137-1721}$ In the present investigation, we have retrospectively evaluated the correlation between haemorrhage from varices and 12 clinical, endoscopic and haemodynamic variables. These variables 
include almost all the factors which could be objectively assessed and have been known to be directly or indirectly associated with variceal bleeding. Based on discriminant function analysis, our results indicate that six of the 12 variables studied, have an important bearing on variceal bleeding. These include in the order of decreasing importance - variceal size, intravariceal pressure, presence of cherry red spots over the varices, colour of varices, presence of red wale markings, and haematocystic spots over the varices.

Our observations indicating that larger varices bleed more often than smaller varices, are in agreement with other workers. ${ }^{1-3}$ There is, however, some confusion and subjectivity in the literature in assessing variceal size. Dagradi and coworkers classified varices into five grades;" Conn grouped them into four grades; ${ }^{+}$Westaby and colleagues categorised them into three grades and Garcia-Tsao et al identified variceal size as either large or small.' Except for Westaby's classification, the other four grading systems (the commonest prototype being Conn's classification) evaluate two aspects of variceal size; the diameter (extent of projection into the lumen) and the circumference of the oesophageal wall occupied by them. Westaby's classification takes into consideration only the diameter of a single varix. According to both the grading systems, larger varices were assessed to bleed significantly more than smaller varices. Conn's grading was found to be slightly more sensitive than Westaby's in correctly predicting variceal bleeding $(88 \%, 78 \%)$, though the difference was not significant. Westaby's variceal grading can be of advantage, in an occasional patient where one sees only a single variceal column instead of the usual three to four columns. There is no specific criteria for variceal size assessment in Japanese Research Society for Portal Hypertension grading system. Evaluation of variceal form is closest to assessing variceal size. While variceal form did correlate with variceal bleeding, assessed individually, it was of little help as it could explain only $3 \%$ variability.

Next to size, intravariceal pressure was the most important variable in predicting variceal blecding. It has been previously shown that intravariceal pressure measured directly, closely reflects intrasplenic pressure. ${ }^{172}$ Measurement of intravariceal pressure is a relatively non-invasive and simple technique and can be performed before routine sclerotherapy. 172 Moreover it reliably reflects portal pressure in patients with non-cirrhotic portal fibrosis and extrahepatic portal hypertension, conditions where wedged hepatic venous pressure underestimates the portal pressure. ${ }^{17}$ Intravariceal pressure was found to be significantly higher $(p<0 \cdot() 1)$ in patients who had bled from varices than non-bleeders even for the same variceal size. In fact, a strong positive correlation $(r=0.59, p<0.001)$ was seen between bleeding and variceal pressure. Amongst bleeders, however, intravariceal pressure did not differ significantly with variceal size. Our findings are supported by the observations of Garcia-Tsao et al' who found that hepatic venous pressure gradient was higher in bleeders than non-bleeders with similar variceal grades. They also found that the gradient did not differ much with variceal size in bleeders. Our results agree that a portal pressure of less than $12 \mathrm{mmHg}$ is rarely associated with variceal bleeding. In fact, as shown in figure 2 , only two of the 72 bleeders had a variceal pressure of less than $12 \mathrm{mmHg}$.

Significant importance has been given by Japanese : ${ }^{*}$ and German" ${ }^{\text {st }}$ workers to the endoscopic appearances of varices. In the present study, we carefully looked for the reliability of these signs. While it was clear that white coloured varices rarely bleed, the converse was not true. Only $63 \%$ of the blue varices had bled. Presence of the red colour signs, namely cherry red spots, red wale markings and hacmatocystic spots was significantly more often associated with variceal bleeding, but it was not discriminatory. Patients with a positive red colour sign also had a significantly $(\mathrm{p}<0 \cdot 001)$ higher mean intravariceal pressure than those in whom this sign was not visible. Similar observations have also been reported by Kleber and coworkers. ${ }^{i c}$ These investigators did not correlate variceal pressure or red colour signs with the frequency of variceal bleeding.

Non-cirrhotic portal fibrosis and extrahepatic portal vein obstruction are very common causes of portal hypertension in developing countries such as India. The initial presentation of the majority of patients with these diseases is with variceal bleeding. ${ }^{1 \times 2 m-2 x}$ In the present series of 126 patients, $47 \%$ paticnts had cirrhosis, $28 \%$ had non-cirrhotic portal fibrosis, and $24 \%$ had extrahepatic portal vein obstruction. It is to be noted that while only $44 \%$ of the cirrhotics presented with a variceal bleed, $66 \%$ of the non-cirrhotic portal fibrosis, and $70 \%$ of the extrahepatic portal vein obstruction patients presented with a variceal bleed. Intravariceal pressure was not significantly different in patients with the three different actiologies of portal hypertension indicating that intravariceal pressure is probably not responsible for the higher frequency of bleeding in non-cirrhotic portal fibrosis and extrahepatic portal vein obstruction. It seems reasonable to assume that as patients with non-cirrhotic portal fibrosis and extrahepatic portal vein obstruction have good liver functions ${ }^{12 m_{2}-2}$ unlike cirrhotics, they present only after a variceal bleed or with symptoms caused by a massive splenomegaly. 
While it is known that after a bleed, patients with Child's $\mathrm{C}$ cirrhosis have a less favourable prognosis than patients with Child's $\mathrm{A},{ }^{19}$ it is uncertain whether the former bleed more often than the latter. Our results did not reveal any significant difference in the blecding rates of patients with different Child's grades of liver disease. These observations, however, should be interpreted with caution as the population of portal hypertension patients in the West almost totally consists of cirrhotics. In the present study, $53 \%$ of the patients did not have cirrhosis of the liver and the majority of the cirrhotics belonged to Child's A class of liver disease.

One of the important observations of our study was that even after collectively evaluating all the 12 known variables, only $54 \%$ variability for predicting variceal bleeding could be explained. In other words, there remained other variables influencing variceal bleeding, which are either unknown or cannot be evaluated at present. In the latter group falls an important variable, the thickness of the variceal wall. Groszmann suggested with the help of La Place's law $\{\mathrm{T}=\mathrm{TP}(\mathrm{r} / \mathrm{w})$, where $\mathrm{T}$ is the variceal wall tension, $T P$ is the transmural pressure - that is, the gradient across the wall and $r$ is the radius of the varix and $w$ is the thickness of the varix $\},{ }^{24}$ that the wall tension increases out of proportion to the rise in pressure in blood vessels. ${ }^{31}$ This is because a rise in the pressure causes an increase in the radius and a decrease in the wall thickness. Unfortunately, at present the applicability of La Place's law is hypothetical, because there is no known technique to measure the thickness of the variceal wall accurately. Endoscopic ultrasound may be of help in the future. ${ }^{31}$

The discriminant function obtained using the six most important predictors was found to be able to correctly identify bleeders from non-bleeders in more than $80 \%$ of the patients with portal hypertension. This investigation combined endoscopic, haemodynamic and clinical parameters and is probably the first concerted report in the literature to correctly identify variceal bleeders. While the discriminant function equation developed is expected to be helpful in correctly predicting variceal bleeders, the search for the unknown variables influencing variceal bleeding should continue.

We are grateful to the Indian Council of Medical research for partial financial assistance in carrying out this study.

\section{References}

1 Garcia-Tsao G, Groszmann RJ, Fisher RL, Conn HO, Atterbury CE, Glickman M. Portal pressure, presence of gastro-oesophageal varices and variceal blecding. Hepatology 1985; 5: 419-24.
2 Lebrec D, Fleury PD, Rueft B, Nahum H, Benhamou JP. Portal pressure. size of oesophageal varices and risk of gastrointestinal bleeding in alcoholic cirrhosis. Gastroenterology 1980; 79: 1139-44.

3 Witzel L, Wolbergs E, Merki H. Prophylactic endoscopic sclerotherapy of oesophageal varices. Lancet 1985: i: 773-5.

4 Conn HO. Ammonia tolerance in the diagnosis of oesophageal varices. A comparison of the endoscopic. radiologic and biochemical techniques. $J$ Lab Clin Med 1967; 70: 442-51.

5 Westaby D, MacDougall BRD. Malia WM. Theodossi A. William R. A prospective randomized study of two sclerotherapy techniques for oesophageal varices. Hepatology 1983; 3: 681-4.

6 Paquet KJ, Oberhammer E. Sclerotherapy of bleeding oesophageal varices by means of endoscopy. Endoscopy 1978: 10: 7-10.

7 The Italian liver cirrhosis project. Reliability of endoscopy in the assessment of variceal features. J Hepatology 1987; 4: 93-8.

8 Japanese Research Society for Portal Hypertension. The general rules for recording endoscopic findings on oesophageal varices. Jpn J Surg 1980; 10: 84-7.

9 Dagradi AE, Stempie SJ, Owens LK. Bleeding oesophagogastric varices. Arch Surg 1966; 92: 944-7.

10 Kumagaya Y, Makuvchi H. Tsuzuki T, et al. Endoscopic classification of oesophageal varices and its clinical significance. Stomach intestine 1976; 11: 741-5.

11 Sonnha Y, Kohayashi M. Inokuchi M. Evaluation of endoscopic diagnosis for the oesophageal varices. J Clin Surg 1974; 29: 173.

12 Beppu K, Inokuchi K, Koyanagi N, et al. Prediction of variceal hemorrhage by oesophageal endoscopy. Gastrointest Endosc 1981; 27: 213-8.

13 Buset M, Marez BD. Baize M, Bourgeois N, Creneer M. Bleeding oesophagogastric varices: an endoscopic study. Gastrointest Endosc 1987; 32: 241-4.

14 Boyer TD. Portal hypertension and its complications: bleeding oesophageal varices, ascites and spontaneous bacterial peritonitis. In: Zakim D, Boyer TD. Hepatology, a text book of liver disease. Philadelphia: WB Saunders, 1982: 469.

15 Reding P, Urbin D, Grivegnec A, Frere D. Portal venous oesophageal luminal pressure gradient in cirrhosis. Hepatology 1986; 6: 98-100.

16 Mossiman R. Nonagressive assessment of portal hypertension using endoscopic measurement of variceal pressure. Am J Surg 1982; 143: 212-4.

17 Sarin SK, Sethi KK, Nanda R. Measurement and correlation of wedged hepatic, intrahepatic, intrasplenic and intravariceal pressure in patients with cirrhosis and non-cirrhotic portal hypertension. Gut 1987; 28: $260-6$.

18 Sarin SK, Nanda R. Sachdev G. Follow-up of patients after variceal eradication: a comparison of paticnts with cirrhosis, non-cirrhotic portal fibrosis and extrahepatic obstruction. Ann Surg 1986; 204: 78-82.

19 Child CG. Turcotte JG. Surgery of portal hypertension. In: Child CJ, ed. The liver and portal hypertension. Philadelphia: WB Saunders and Co, 1964: 50-85.

20 Sarin SK, Nanda R, Gaur SK, et al. Repeated endo- 
scopic sclerotherapy of ocsophageal varices in children. Ann Surg 1985; 202: 708-11.

21 Butzow GH, Novak D. Clinical value of hepatic vein catheterization. Gastrointest Radiol 1977; 2: 153-61.

22 Straitz M, Pordalla T, Meyerzum Buschenfelde K-H. Intravascular oesophageal pressure (IOVP) assessed by endoscopic fine needle puncture under basal conditions. Valsalva's manoeuvre and after glycerine trinitrate application. Gut 1985; 26: 525-30.

23 Hosking SW, Robinson P. Johnson AG. Usefulness of manometric assessment of varices in maintenance sclerotherapy. Gastroenterology 1987; 93: 846-51.

24 Paquet KH. Koussouris P. Is there an indication for prophylactic endoscopic paravariceal injection sclerotherapy in patients with liver cirrhosis and portal hypertension? Endoscopy 1986; 18 (suppl 2): 32-5.

25 Klever G. Sauerbruch T. Fischer G, Paumgartner G. The red color sign indicates a high oesophageal variceal pressure [Abstract]. Hepatology 1987: 7: 1062.
26 Okuda K. Kono K. Ohnishi K. et al. Clinical study of eighty six cases of portal hypertension and comparison with cirrhosis with splenomegaly. Gastroenterology 1984: 88: 600-10.

27 Sarin SK. Misra SP. Singal AK. Thorat V, Broor SL. Endoscopic sclerotherapy for varices in children. J Pediatr Gastroenterol Nutr 1988; 7: 662-6.

28 Sarin SK. Non-cirrhotic portal fibrosis. Gut 1989; 30: $406-15$.

29 Conn HO, Groszmann RJ. The pathophysiology of portal hypertension. In: Aries 1. Popper D. Schachter D. et al. eds. The liver: biology and pathology. New York: Raven Press, 1982: 821-48.

30 Groszmann RJ. Reassessing portal venous pressure measurements. Gastroenterology 1984; 86: 1611-7.

31 Sukigara M. Ohata M. Komazaki T. Omata R. Assessment of the effect of respiration on the oesophageal variceal blood flow using trans-oesophageal real time two dimensional doppler echocardiography. Hepatology 1988; 8: 663-7. 